\title{
Simulation Analysis of GPS/GLONASS Absolute Positioning Performance in an Urban Canyon Environment
}

\author{
Nam-Hyeok Kim and Chi-Ho Park
}

\begin{abstract}
This paper analyzes the positioning performance of Global Navigation Satellite Systems (GNSSs) in an urban canyon environment. The recently developed telematics technology requires highly accurate and robust positioning performance in urban areas. However, GPS positioning alone fails to provide adequate performance in this environment. In this paper, we developed a simulator and simulated the positioning process in an urban environment in order to analyze the performance of GPS and GLONASS combined positioning. In the results, the positioning possibility was improved but the accuracy was not enhanced when GPS/GLONASS combined positioning was performed. The accuracy was not improved because of geometrical instability. Therefore, for accurate and robust positioning in an urban canyon environment, GNSS should be integrated with other type of sensors such as an Inertial Navigation System or a Vision System.
\end{abstract}

Index Terms-GNSS, GPS, GLONASS, positioning.

\section{INTRODUCTION}

Global Navigation Satellite Systems (GNSSs), such as the Global Positioning System (GPS) in the USA, the GLObal NAvigation Satellite System (GLONASS) in Russia, and the Galileo in the EU, determine a receiver's position using propagation time of arrival [1]. The satellites' visibility from a given antenna is thus an important factor for GNSS positioning [2]. However, satellites' signals sometimes are occluded by skyscrapers and other obstacles in an urban canyon environment, thus decreasing the number of satellites. Positioning error consequently rises and it is not possible to calculate the receiver's coordinates. Recently developed telematics technology requires high accuracy and robust positioning performance in urban areas. For this reason, many researchers and developers are trying to increase the number of visible satellites by using GPS and GLONASS simultaneously. In this study, we developed a simulator and simulated the positioning process in an urban environment in order to analyze the performance of GPS and GLONASS combined positioning.

GPS and GLONASS are types of GNSS, and in this regard are very similar. Nonetheless, there are some differences, which are described in section 2.

Manuscript received September 21, 2015; revised November 20, 2015. This work was supported by the DGIST R\&D Program of the Ministry of Science, ICT and Technology of Korea (15-IT-01).

The authors are with the Division of IoT and Robotics Convergence Research, DGIST, Daegu, South Korea (e-mail: nhkim@dgist.ac.kr, chpark@dgist.ac.kr).
In Section III, the configuration of the simulator developed using MATLAB is described. The developed simulator generates GPS and GLONASS observation data with a variety of errors, such as ionospheric delays, tropospheric delays, clock error, etc. Moreover, the simulator loads an 3D electronic map and filters some signals that are blocked by some buildings in the map.

Using the developed simulator, GPS, GLONASS, and GPS/GLOANSS positioning is performed and errors in the simulated environment are analyzed. This is described in Section IV.

Through this simulation study, as presented in Section V, we found that the positioning error of GNSSs does not decline even when using a sufficient number of satellites due to geometrical instability.

This paper starts with a comparison of GPS/GLONASS in Section II, followed by a description of the simulator in Section III. In Section IV, the performance of GPS, GLONASS, and GPS/GLONASS, respectively, is analyzed. Finally, the conclusion of this paper is presented in Section V.

\section{GPS AND GLOANSS}

GPS and GLONASS are basically similar. Both systems receive the signal and calculate the length of the signal and then compute the coordinates by using the length. But they have some differences that need to be taken into account when performing combined processing and a performance analysis, such as different geodetic reference systems (WGS-84 versus PZ-90), time reference, orbital plane inclination, etc. Looking at some of the differences, GLONASS's orbital plane inclination is 64.8 degrees, and it is thus advantageous for satellite visibility for Europe because Russia is located at high latitudes. Compared with GPS's CDMA (Code Division Multiple Access), GLONASS's signal separation technique is FDMA (Frequency Division Multiple Access). The satellite ephemeris of GPS is specified by Keplerian orbital elements and perturbation factors. However, GLONASS's satellites ephemeris is specified in geocentric Cartesian coordinates and their derivatives. This should be considered for computing satellites' coordinates. GPS and GLONASS have different time systems. Because GLONASS uses UTC (Soviet Union), leap second adjustment is also considered for combined positioning. More details are provided in Table I [3].

Although there are some differences in the two systems the same positioning algorithm can be applied when an appropriate transformation is applied [4]. 
TABLE I: GPS AND GLONASS COMPARISON

\begin{tabular}{|c|c|c|c|}
\hline & Details & GPS & GLONASS \\
\hline \multirow{4}{*}{ 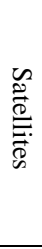 } & $\begin{array}{l}\text { Number of satellites for } \\
06 / 2013\end{array}$ & 30 & 24 \\
\hline & Number of orbital planes & 6 & 3 \\
\hline & $\begin{array}{l}\text { Orbital plane } \\
\text { inclination(degrees) }\end{array}$ & 55 & 64.8 \\
\hline & Orbital radius $(\mathrm{km})$ & 26560 & 25510 \\
\hline \multirow{8}{*}{ 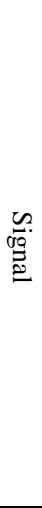 } & $\begin{array}{l}\text { Fundamental clock } \\
\text { frequency }(\mathrm{MHz})\end{array}$ & 10.23 & 5 \\
\hline & Signal separation technique & CDMA & FDMA \\
\hline & $\begin{array}{l}\text { Carrier frequencies }(\mathrm{MHz}) \\
\mathrm{L} 1\end{array}$ & 1575.42 & $\begin{array}{l}1598.0625 \sim \\
1609.3125\end{array}$ \\
\hline & $\begin{array}{l}\text { Carrier frequencies }(\mathrm{MHz}) \\
\mathrm{L} 2\end{array}$ & 1227.6 & $\begin{array}{l}1242.9375 \sim \\
1251.6875\end{array}$ \\
\hline & Code clock rate $(\mathrm{MHz}) \mathrm{C} / \mathrm{A}$ & 1.023 & 0.511 \\
\hline & Code clock rate $(\mathrm{MHz}) \mathrm{P}$ & 10.23 & 5.11 \\
\hline & Code length(chips) C/A & 1023 & 511 \\
\hline & Code length(chips) $\mathrm{P}$ & $\begin{array}{l}6.187104 x \\
1012\end{array}$ & $5.11 \times 106$ \\
\hline \multirow{8}{*}{ 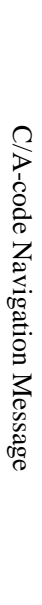 } & $\begin{array}{l}\text { Superframe duration } \\
\text { (minutes) }\end{array}$ & 12.5 & 2.5 \\
\hline & Superframe capacity (bits) & 37,500 & 7,500 \\
\hline & $\begin{array}{l}\text { Superframe reserve } \\
\text { capacity (bits) }\end{array}$ & $\sim 2,750$ & $\sim 620$ \\
\hline & Word duration (seconds) & 0.6 & 2 \\
\hline & Word capacity (bits) & 30 & 100 \\
\hline & $\begin{array}{l}\text { Number of words within a } \\
\text { frame }\end{array}$ & 50 & 15 \\
\hline & $\begin{array}{l}\text { Technique for specifying } \\
\text { satellite ephemeris }\end{array}$ & $\begin{array}{l}\text { Keplerian } \\
\text { orbital } \\
\text { elements and } \\
\text { perturbation } \\
\text { factors }\end{array}$ & $\begin{array}{l}\text { Geocentric } \\
\text { Cartesian } \\
\text { coordinates } \\
\text { and their } \\
\text { derivatives }\end{array}$ \\
\hline & Time reference & UTC(USNO) & UTC (SU) \\
\hline
\end{tabular}

TABLE II: SIMULATED MODELING ERROR [1]

\begin{tabular}{|c|c|c|}
\hline & Error & Error model \\
\hline \multirow{2}{*}{$\begin{array}{l}\text { Satellite-dependent } \\
\text { error }\end{array}$} & GPS orbit & $\begin{array}{l}\text { Broadcast ephemerides } \\
\text { (IGS orbit) }\end{array}$ \\
\hline & $\begin{array}{l}\text { Satellite clock } \\
\text { error }\end{array}$ & $\begin{array}{l}\text { Final clock file (IGS clock } \\
\text { file) }\end{array}$ \\
\hline \multirow{2}{*}{$\begin{array}{l}\text { Atmosphere-induced } \\
\text { error }\end{array}$} & $\begin{array}{l}\text { Ionospheric } \\
\text { delay }\end{array}$ & $\begin{array}{l}\text { IGS TEC (total electron } \\
\text { content) map }\end{array}$ \\
\hline & $\begin{array}{l}\text { Tropospheric } \\
\text { delay }\end{array}$ & $\begin{array}{l}\text { Saastamoinen model [5], } \\
\text { Chao mapping function [6] }\end{array}$ \\
\hline \multirow[b]{2}{*}{ Receiver error } & $\begin{array}{l}\text { Receiver clock } \\
\text { error }\end{array}$ & $\begin{array}{l}\text { Two-state random process } \\
\text { model[7] }\end{array}$ \\
\hline & $\begin{array}{l}\text { Differential } \\
\text { Code Bias } \\
(\mathrm{DCB})\end{array}$ & $\begin{array}{l}\text { CODE (center for orbit } \\
\text { determination in Europe) } \\
\text { DCB file }\end{array}$ \\
\hline \multirow[b]{2}{*}{ Other error } & Random error & $0.3 \mathrm{~m}$ \\
\hline & $\begin{array}{l}\text { Relativity } \\
\text { affecting the } \\
\text { earth rotation }\end{array}$ & Sagnac effect \\
\hline
\end{tabular}

\section{SIMULATOR}

The simulator developed using MATLAB for this study consists of 4 modules. The urban environment data generating module loads a 3D electronic map and generates reference position data. The GPS and GLONASS data generating module renders the GPS and GLONASS observation data similar, and then exports the data in the RINEX (Receiver Independent Exchange Format) format. The error data generating module calculates observation errors based on each model. Simulated modeling errors are presented in Table II.

Finally, positioning is performed by using the Gauss-Markov Theorem and errors are calculated through comparison with reference position data and Fig. 1 shows the configuration of the simulator.

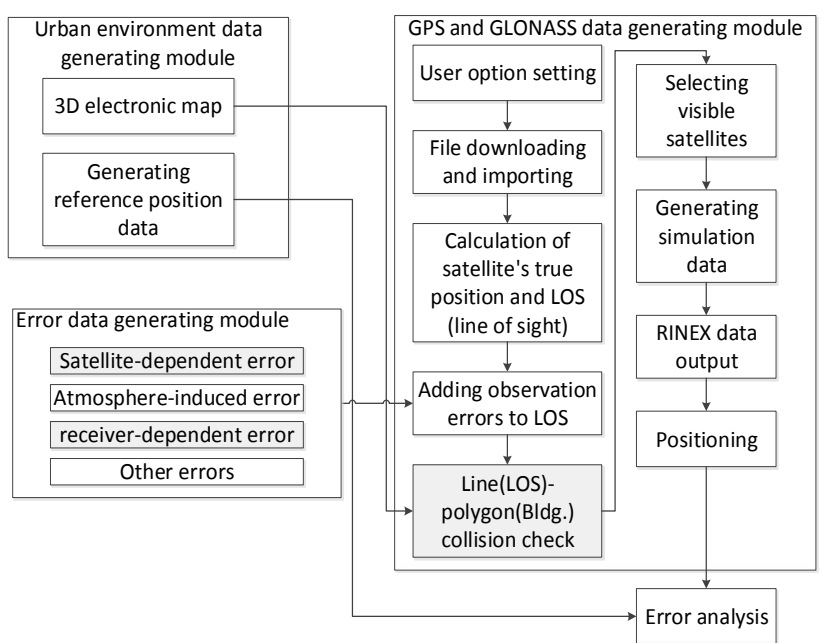

Fig. 1. Configuration of the simulator.

In more detail about the code positioning, the code observation equation for the navigation satellites system is given as follows.

$$
\begin{aligned}
& P_{i, 1}^{k}=\rho_{i}^{k}+T_{i}^{k}+\frac{I_{i}^{k}}{f_{1}^{2}}+c\left(d t_{i}-d t^{k}\right)+e_{i, 1}^{k} \\
& \rho_{i}^{k}=\sqrt{\left(x^{k}-x_{i}\right)^{2}+\left(y^{k}-y_{i}\right)^{2}+\left(z^{k}-z_{i}\right)^{2}}
\end{aligned}
$$

where, $i$ and $k$ denote receiver and satellite, respectively.

$P_{i, 1}^{k}$ : code pseudorange between the receiver and the satellite (m);

$\rho_{i}^{k}:$ actual geometric distance between receiver and satellite (m);

$T_{i}^{k}:$ tropospheric delay error (m);

$\frac{I_{i}^{k}}{f_{1}^{2}}:$ ionosphereric delay error $(\mathrm{m})$;

$c$ : speed of light $(\mathrm{m} / \mathrm{s})$;

$d t_{i}:$ receiver clock error $(\mathrm{sec})$;

$d t^{k}$ : satellite clock error (sec);

$e_{i, 1}^{k}:$ measurement error.

Ionospheric delay effects and satellite clock errors are removed by a navigation message from the satellites. Tropospheric delay effects are removed by models that account for the dry and wet refractivity at the surface of the Earth. The inter-frequency bias is ignored because of its small 
value. As a consequence, Equation (2) can be used for the measurement equation to compute the receiver's position in 3-dimensional space.

$$
P_{i, 1}^{k}-T_{i}^{k}-\frac{I_{i}^{k}}{f_{1}^{2}}+c d t^{k}=\rho_{i}^{k}+c d t_{i}+e_{i, 1}^{k}
$$

Equation (2) can be rewritten in matrix form after the linearization as follows:

$$
y=A \xi+e, \quad e \sim\left(0, \sigma_{0}^{2} P^{-1}\right)
$$

Each item is shown below, $\dot{\rho}$ is calculated by the receiver's initial position $\left(\dot{x}_{i}, \dot{y}_{i}, \dot{z}_{i}\right)$.

$$
\begin{aligned}
& y=\left[\begin{array}{ccc}
P_{i, 0}^{k} & - & P_{i, c}^{k} \\
P_{i, 0}^{l} & - & P_{i, c}^{l} \\
& \vdots & \\
P_{i, 0}^{q} & & P_{i, c}^{q}
\end{array}\right]: \text { Observation vector } \\
& A=\left[\begin{array}{cc}
-\frac{x^{k}-\dot{x}_{i}}{\dot{\rho}_{i}^{k}}-\frac{y^{k}-\dot{y}_{i}}{\dot{\rho}_{i}^{k}}-\frac{z^{k}-\dot{z}_{i}}{\dot{\rho}_{i}^{k}} & c \\
-\frac{x^{l}-\dot{x}_{i}}{\dot{\rho}_{i}^{l}}-\frac{y^{l}-\dot{y}_{i}}{\dot{\rho}_{i}^{l}}-\frac{z^{l}-\dot{z}_{i}}{\dot{\rho}_{i}^{l}} & c \\
\vdots & \\
-\frac{x^{q}-\dot{x}_{i}}{\dot{\rho}_{i}^{q}}-\frac{y^{q}-\dot{y}_{i}}{\dot{\rho}_{i}^{q}}-\frac{z^{q}-\dot{z}_{i}}{\dot{\rho}_{i}^{q}} & c
\end{array}\right] \text { : Design matrix } \\
& \xi=\left[\begin{array}{c}
\Delta x_{i} \\
\Delta y_{i} \\
\Delta z_{i} \\
d t_{i}
\end{array}\right]: \text { Unknown parameter vector } \\
& e=\left[\begin{array}{c}
e_{i}^{k} \\
e_{i}^{l} \\
\vdots \\
e_{i}^{q}
\end{array}\right]: \text { Measurement error vector }
\end{aligned}
$$$$
n \times 1
$$

Then, the adjustment computation can be performed to estimate the parameters. Equation (4) shows the estimated parameters, i.e., the increments with respect to the initial values.

$$
\hat{\xi}=\left(A^{T} P A\right)^{-1} A^{T} P y
$$

The increment from (4) is added to the receiver's initial position and then the receiver's position is updated. This process is iterated until the increment is under the particular threshold value. After this process, the receiver's position is determined.

$$
\left[\begin{array}{c}
x_{i} \\
y_{i} \\
z_{i}
\end{array}\right]_{\text {update }}=\left[\begin{array}{c}
x_{i} \\
y_{i} \\
z_{i}
\end{array}\right]_{\text {initial }}+\left[\begin{array}{c}
\Delta x_{i} \\
\Delta y_{i} \\
\Delta z_{i}
\end{array}\right]
$$

The variance component can be computed by using (6). Also, the variance-covariance matrix for the estimates can be obtained using (7).

$$
\hat{\sigma}_{0}^{2}=\frac{\tilde{e}^{T} P \tilde{e}}{n-r k(A)}
$$

where, $\tilde{e}=y-A \hat{\xi}, n$ is the number of observations, $r k(A)$ is the rank of $A$.

$$
D\{\hat{\xi}\}=\sigma_{0}^{2} N^{-1}
$$

where, $N$ is the noromal matrix $\left(N=A^{T} P A\right)[8]$.

For using this simulator, a $3 \mathrm{D}$ electronic map was made based on a national digital map. The selected area represents an urban canyon environment. In this area, there are some buildings that exceed 40 floors. Fig. 2 shows an aerial photo of the selected area.

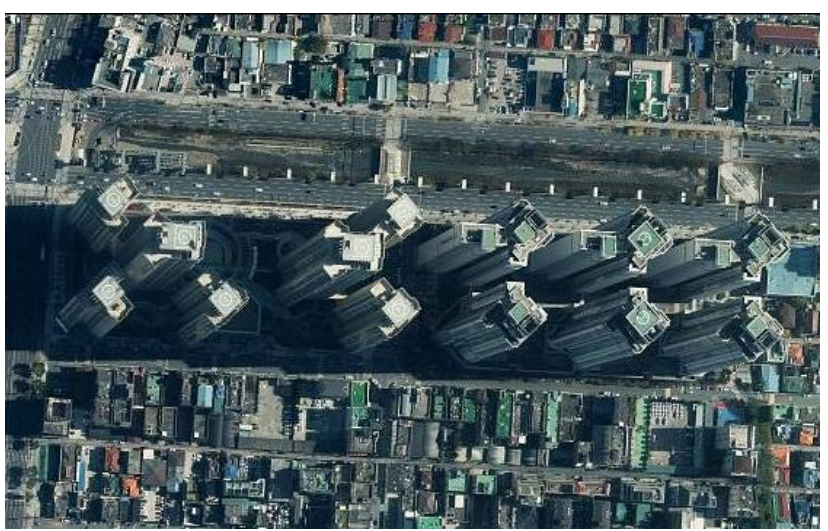

Fig. 2. Simulated environment (Daegu, S.KOREA)

It is assumed that the rover's trajectory moves around the high buildings and the observation time is from 01:00:00 to 02:04:00 Jan. 15, 2015(total 3,847 epoch). For a precise analysis of the positioning, slow movement is assumed. Fig. 3 shows the $3 \mathrm{D}$ electronic map and the rover's trajectory.

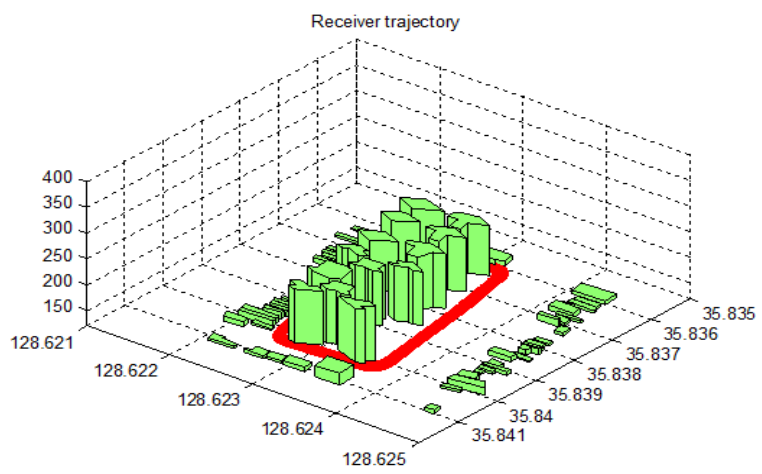

Fig. 3. 3D electronic map and rover's trajectory.

All coordinates related with the map and positioning results are produced in Earth-Centered Earth-Fixed (ECEF) coordinates and converted to geodetic coordinates (latitude, longitude, and altitude) and North-East-Down coordinates for a convenient analysis.

\section{Positioning PERformance ANALYSIS}

The observation data were generated by using the 
simulator, and GPS, GLONASS, GPS/GLONASS combined positioning was performed. The positioning results for the analyzed area were compared with the reference position data.

Fig. 4 shows the horizontal positioning results in geodetic coordinates and Table III presents the analysis results in NED coordinates.

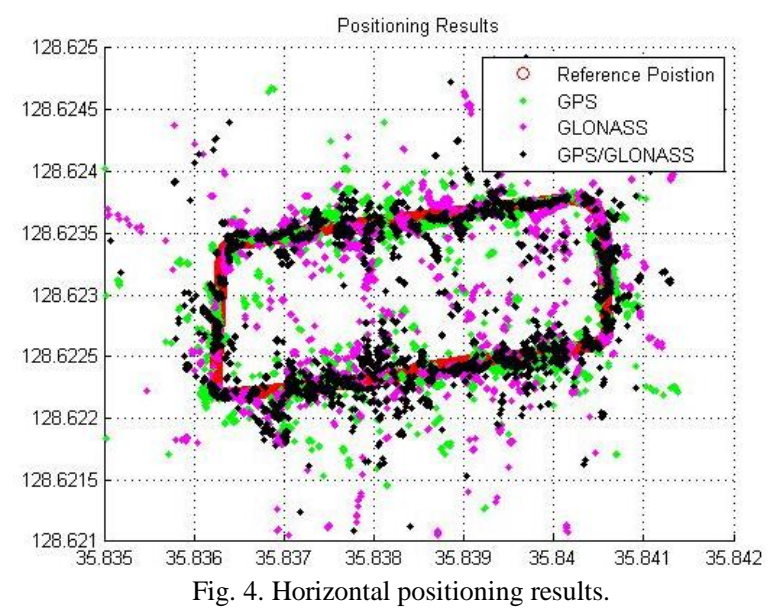

TABLE III: POSITIONING ERROR AND NUMBER OF POSITIONING

\begin{tabular}{cccc}
\hline \hline & GPS & GLONASS & GPS/GLONASS \\
\hline Root Mean Square Error(m) & 35.04 & 48.69 & 30.14 \\
Number of Positioning & 3,678 & 3,674 & 3,842 \\
\hline \hline
\end{tabular}

As can be seen from the table, the number of positioning increased when GPS/GLONASS combined positioning was performed, but the accuracy was not improved. While there are some factors that may explain why the accuracy was not improved, the main reason is geometric stability. For verification of the geometric stability, a DOP (Dilution Of Precision) analysis was carried out. DOP is a measure of the instantaneous geometry and the geometry is stable when the DOP values are lower.

DOP can be calculated from the inverse of the normal equation matrix. The cofactor matrix of the parameters $Q_{X}$ follows from

$$
Q_{X}=\left(A^{T} A\right)^{-1}
$$

Capital $X$ is used here as an indication of coordinates of and ECEF system. The cofactor matrix $Q_{X}$ is a [4×4] matrix, where three components are contributed by the site position $X$, $Y, Z$ and one component by the receiver clock. Denoting the elements of the cofactor matrix as

$$
Q x=\left[\begin{array}{llll}
q_{X X} & q_{X Y} & q_{X Z} & q_{X t} \\
q_{X Y} & q_{Y Y} & q_{Y Z} & q_{Y t} \\
q_{X Z} & q_{Y Z} & q_{Z Z} & q_{Z t} \\
q_{X t} & q_{Y t} & q_{Z t} & q_{t t}
\end{array}\right]
$$

the diagonal elements are used for the geometric DOP (GDOP) definitions [9].

$$
G D O P=\sqrt{q_{x x}+q_{y y}+q_{z z}+q_{n}}
$$

Generally, GNSS can compute accurate position coordinates when GDOP values are under 3. Figure 5 below shows the GDOP values of the positioning simulation.

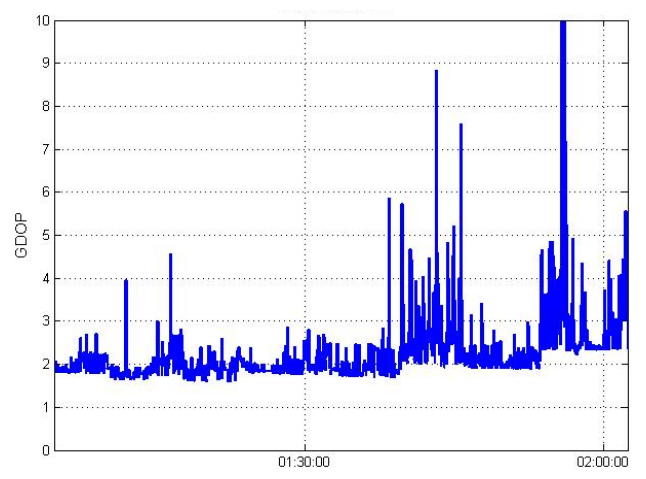

Fig. 5. GDOP of the positioning simulation.

As seen in the figure, GDOP values peaked in some epochs. This means geometrical stability is unstable in that epoch. Conclusively, the positioning possibility can be improved when GPS/GLONASS combined positioning is performed. This is a result of increasing the number of visible satellites. However, GDOP is not improved because the visible sky area is restricted by building and consequently the positioning accuracy is not improved.

\section{CONCLUSION}

In this paper, the positioning performance of GPS, GLONASS, and GPS/GLONASS was respectively analyzed in an urban canyon environment by using a simulator developed by the authors. In the results, the positioning possibility was improved but the accuracy was not enhanced when GPS/GLONASS combined positioning was performed. The accuracy was not improved because of geometrical instability. Even when the number of satellites was increased, the placement of visible satellites was not good for positioning in an environment with tall buildings. This was verified by analyzing GDOP values. Therefore, for accurate and robust positioning in an urban canyon environment, GNSS should be integrated with other type of sensors such as an Inertial Navigation System or a Vision System.

\section{REFERENCES}

[1] N. H. Kim, C. H. Park, and S. K. Jung, "Simulation analysis for performance improvements of GNSS-based positioning in a road environment," presented at the Sixth International Conference on Advances in System Simulation, Nice, France, Oct. 12, 2014.

[2] B. H. Lee, G. I. Jee, J. O. Kim, and J. H. Ko, "Evaluation of positioning performance for combined GPS and GLONASS in Urban area," presented at the Korean Institute Communication and Information Sciences Summer Workshop, Korea, June 22-24, 2009.

[3] W. Y. Park, I. S. Lee, and J. S. Kim, "The capability comparison of positioning performances using GPS and GPS/GLONASS," Journal of the Korean Society for Geospatial Information Science, vol. 9, no. 1, pp. 59-66, June 2001.

[4] A. E. Zinoviev, "Using GLONASS in combined GNSS receivers: Current Status," in Proc. ION GNSS, California, 2005, pp. 1046-1057.

[5] J. Saastamoinen, "Contributions to the theory of atmospheric refraction,” Bulletin Géodésique, vol. 107, pp. 13-34, Mar. 1973.

[6] C. C. Chao, "A model for tropospheric Calibration from daily surface and radiosonde balloon measurements," Technical Memorandum of Jet Propulsion Laboratory, pp. 391-350, 1972.

[7] B. W. Parkinson and J. J. Spilker, Global Positioning System: Theory and Applications, Springer-Wien New York, 1997, vol. 1, pp. 389-399. 
[8] N. H. Kim and C. H. Park, "Precise and reliable positioning based on the integration of navigation satellite system and vision system," International Journal of Automotive Technology, vol. 15, pp. 79-87, Feb. 2014.

[9] B. Hofmann-Wellenhof, H. Lichtenegger, and E. Wasle, "GNSS-global navigation satellite systems: GPS, GLONASS, galileo, and more," Springer-Wien New York, pp. 263-265, 2007.

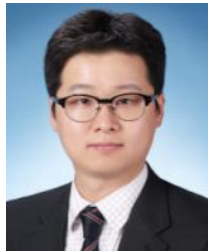

Nam-Hyeok Kim received a master degree in spatia information engineering from Kyungpook National University, Korea in 2014. He received a bachelor degree in spatial information engineering from University of Seoul, Korea in 2009. He is currently studying positioning for unmanned vehicles in DGIST (Daegu Gyeongbuk Institute of Science \& Technology) and $\mathrm{PhD}$ studies in Kyungpook National University. His research interests include electronic maps for unmanned vehicles.

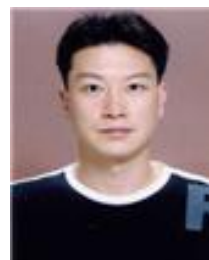

Chi-Ho Park received $\mathrm{PhD}$ and master degrees in electroninc communication engineering from Kwangwoon University, Korea in 2001 and 2008. He is currently studying positioning for unmanned vehicles in DGIST (Daegu Gyeongbuk Institute of Science \& Technology). 